\title{
FROM END-STATE FIT TO FITTING DYNAMIC: IMPLICATIONS FOR ORGANIZATIONAL STUDIES
}

\author{
Janice A. Black \\ New Mexico State University \\ Las Cruces, NM
}

\begin{abstract}
Austrian economics is a disequilibrium-based understanding of how firms interact in markets. Using hasic concepts from Austrian economics and the market dynamics implied from them, this paper presents a dynamic view of fitting as one of the implications for organization studies and highlights other critical areas including entrepreneurship, innovation, information processing and organizational learning and change.
\end{abstract}

'Fit' has long been a central focus in the strategy and contingency literatures (Van de Ven and Drazin, 1985; Summer, Bettis, Dulhaime, Grant, Hambrick, Snow \& Zeithaml, 1990). Generally, fit has been conceptualized as a specific end-goal implying an attainable fit is possible (i.e. fit measured against an ideal or best performer, (Doty, Glick \& Huber 1993)). This conceptualization implies the following: 1) that clear links exist between cause and effect (otherwise fit could not be the specific end-goal), 2) that conditions present in the environment will continue (otherwise what is useful now may not be in the future) and 3) that the use of negative feedback enables the determination of the set of requirements needed for fit (otherwise the distance from any specified set of requirements is useless). These assumptions correspond to those needed in an equilibrium-based market economy (Stacey, 1995; Hunt, 2000).

Recently the usefulness of the foundational assumptions of equilibrium-based economics has been questioned (McWilliams and Smart, 1995). Austrian economics (Kirzner, 2000; Scarth, 1988; Stacey, 1995;) or ideas based in Austrian economics (Peteraf \& Ferrier, 2002; McWilliams and Smart, 1995; Hunt, 1995; 1998,2000 ) have been offered as an alternative. Yet there are implications for organizational studies, if we switch the assumption base, which have not been addressed. Austrian economics is a disequilibrium-based system that has characteristics that mirror those of complex systems (Stacey, 1995). Such characteristics include: 1) causal links are nonlinear, 2) results are partially planned and partially emergent, and 3) specific predictions of outcomes are problematic. This implies that we need to revisit our concept of fit because, as this paper develops, under these conditions, fit becomes an apparition that organizations chase. This paper presents the dynamics of the fitting process in a complex system based on the underlying explanation provided by Austrian economics. It 
finishes with outlining some critical areas of research arising from exploring a disequilibrium-based understanding of market forces.

\section{Fit, Fitting and the Impact of Market Dynamics}

\section{Fit}

When using a system that has a stable structure, it is possible to determine a stable end point, a goal at which to aim. The agent taking aim has to handle the uncertainly that is inherent in any future oriented action, but coping with that uncertainty is doable. This is the basis for decisions from an equilibriumoriented system. Uncertainty that is present is a result of an error. Certain actions lead predictably to an erosion of supra-normal returns and ultimately to equilibrium return levels (Hunt, 2000).

Unlike in equilibrium systems, the existence of uncertainty is a base assumption of Austrian economics (Kirzner, 2000, 1982; Mises, 1949; Hayek, 1948b; Schumpeter, 1934). Under Austrian economics imperfectly implemented plans contribute to uncertainty about the future (Mises, 1949). People as economic agents cope with this uncertainty (Kirzner, 1982; Mises, 1949). Reasonable people will still make mistakes, be inefficient and even fail, but this does not mean that they acted irrationally (Mises, 1957). This view accords all action as being future oriented (Kirzner, 1978); by this is meant that people see their actions as linked to a possible future result. This being the case, they will try to place themselves in the 'best' of equally available positions (Kirzner, 1978).

If that positioning attempt fails, then one of three possibilities has occurred. 1) The successful position was not available (attributable to an error in judgement or execution; Kirzner, 1978). 2) The economic agent was not aware of the successful position (attributable to an error in collecting information; March and Simon, 1992). 3) The environment shifted changing the definition of a successful position (attributable to emergent or unpredicted systemic change (Stacey, 1995; McWilliams \& Smart, 1995; Mintzberg \& Waters, 1985; Schumpeter, 1934). The second case requires further elaboration. Even though the agent was not aware that the information was available, it is an example of the economic error of not acting upon information (Jacobson, 1992). The existence of the element of unawareness is not impossible (as assumed in rational expectations in the Keynesian view; Scarth, 1988) because purposeful action by itself does not mean that all opportunities are instantaneously perceived (Kirzner, 1978). Purposeful action seeks out opportunities or tries to take advantage of them (O'Driscoll, 1977), but it is unreasonable to expect that everyone will have similar perceptions, reactions or expectations about the results of actions (Lachmann, 1977).

Some of the variance in perception, reaction, and expectation can be traced to variances in the way people perceive, receive, and interpret information (Bamford, Rogers, \& Miller, 1999). Thus, a key issue in purposeful action is the acquisition and dispersal of information. The critical basis of these skills is not 
just related to the variation mentioned earlier but also because applied information or knowledge enables the management of the uncertainty inherent in any purposeful action, which addresses the future. To the Austrian economist, the market is a 'process of learning and discovery, rather than an equilibrium state of affairs' (Klein, 1992:2). The market assumption is 'not on human rationality, but on human ignorance' (Klein, 1992:4). Information is assumed to never be fully dispersed or completely utilized.

The process of acquiring the information and acting upon it corresponds to the actions firms engage in to 'fit' with their environments. Yet from the Austrian perspective, the collective 'firm' is really the set of individuals acting in alignment. Thus individual entrepreneurial actions are the appropriate level of analysis.

\section{Entrepreneurial Fitting}

In an unstable and unpredictable system, having specific end goals is problematic (McWilliam \& Smart, 1995). Thus, using a specific end goal as a directional guidance device may not be useful. When system changes are occurring, it may be more important to respond to and enact changes than strive towards a point determined earlier but which, as events unfold, appears to not be as attractive (Argyres \& McGahan, 2002).

Action (or dynamism of the market) occurs via entrepreneurs according to Austrian economics (Kirzner, 2002, 1982). Entrepreneurial activities are defined as the function of making decisions and taking actions in the face of an uncertain present or future environment and the realization of existing opportunities that have remained previously unnoticed (Kirzner, 1982). Venkatraman (1997) expands this definition and places it soundly in the academic realm by noting that the study of entrepreneurship is studying not only the who-does what-how aspect but also includes how the opportunities are discovered, evaluated and exploited. Since it is reasonable to assume that the purposeful person is acting upon his imagined future (Mises, 1949) and that his actions impact the actual future (Giddens, 1979), the closer his imagined future is to the actual, the more successful his plans (Kirzner, 1978). An individual's motivation to imagine a future as close to actuality as possible is the desire for the rewards generated by the successful completion of his plans.

Entrepreneurial alertness is the scanning of the environment and the interpreting of it to construct that envisioned future (Kirzner, 1982). Entrepreneurial alertness remains somewhat of a mystery (Gaglio and Katz, 2001). Alertness includes noticing and reacting to what is unfolding, as well as the taking of a proactive stance (one which initiates changes). This duality has caused problems in conceptualization (Gaglio and Katz, 2001) with equivocal empirical research resulting. While both passive and active elements are included in the definition that is used in this paper, it is the proactive nature of action-taking that is critical here. Such proactive behavior is seen in imaginative and creative leaps of faith that can result in the creation of the imagined future for which the present 
acts were designed (the alignment of the imagined future with the actual future due to the entrepreneur's actions). Not all such attempts will succeed and some successes will later be invalidated; nevertheless, this implies that the scope for entrepreneurial activity is provided by the degree of uncertainty about the future and that the correct use of entrepreneurial alertness is rewarded by the increased success of the entrepreneur's plans (Kirzner, 1982).

While the market is the byproduct of the entrepreneurs' activities, the entrepreneur can be said to have the market function of "bring(ing) different parts of the market into coordination with each other" (Kirzner, 1982: 136). The degree to which the market is in equilibrium depends on the entrepreneur's activities (Griner, 1977) which can also be seen as the act of 'fitting' the entrepreneur's firm to the environment. As a market equilibrium is reached, it reduces the range of entrepreneurial activity for that particular market (Kirzner, 1979). This implies that the better the organization 'fits' the market (as revealed by higher 'returns' or 'rewards'), the more opportunities have been spotted and acted upon via individual entrepreneurial actions. Organizational 'fit' is a by-product of these 'fitting' activities.

\section{Impact of Market Dynamics}

From the above two discussions on the actions and results of actions in a marketplace, it is evident that the interactions in the market impact the goals and processes of the agents. Specifically, it is in the market coordination efforts that goals can become displaced (Hunt, 1995). Because in the Austrian school's perspective, the concept of market equilibrium is a reflection of the coordination process, change in the market is moved from being exogenous to endogenous. The change occurs as entrepreneurs make decisions and act upon them (Kirzner, 1979). The market is shaped by these decisions and activities along with the diffusion of the knowledge revealed and created by the entrepreneurial activity (Lachmann, 1977).

This entrepreneurial seeking, collecting, acting upon and disseminating of knowledge results in a model that is based on a capital stock that is heterogeneous and which is integrated into a structure of production (Garrison, 1978). The capital structure of any firm within the market is not assumed to be a miniature replication of the market but rather a reflection of the entrepreneur who created the combination of the elements of the capital structure (Lachmann, 1977). These structures may be reshuffled as entrepreneurs realize better uses for their resources (Schumpeter, 1934). Their economic returns may be eroded as competition increases due to the other entrepreneurs' choice to compete based on those others becoming aware of the opportunity represented by the resource combination due to their alert scanning of the environment but they never reach equilibrium (Hayek, 1948a).

Although the entrepreneurs attempt coordination efforts, they are impeded in the attempt time and time again by others attempting to do the same thing. In other words, the dissemination of knowledge, the inflow of new knowledge 
(technology changes, changes in human social tastes), and "the spontaneous action of the alert minds of participants inspired, but not compelled, by what they witness on the market scene around them" (Lachmann, 1977: 40). Thus from the above we see that economics actors both work towards coordination and against coordination. With this perspective, the market place is not characterized by a state of equilibrium but rather by a series of disequilibria that, as information is shared, moves closer to states of equilibria (Kirzner, 1982). Returns above the expected level of investors and the level needed for firm survival are probable in this disequilibrium-based market (McWilliams \& Smart, 1995).

This understanding allows us to realize that any ' $\mathrm{fit}$ ' that has been attained is transitory. As individuals act, the impact of those actions changes the very system that inspired them. This means that focusing on sensemaking of the past actions and cause-effect relationships informs future actions only to the degree to which the 'system' has remained the same. In systems where change is the norm and where change is not rhythmically predictable, other decision rules than past-based sensemaking will be more appropriate (McWilliams \& Smart, 1995).

\section{Issues to Consider From Equilibrium Versus Disequilibrium Focuses}

\section{Equilibrium Focuses}

In an equilibrium-based system such as classical economics, the system has a 'center of gravity' to which prices gravitate, an equilibrium point (Addleson, 1994). At the equilibrium point, sufficient profits are earned to reward the investor's expectation of return and allow firm survival (Hunt, 1995; Rumelt, Schendel, \& Teece, 1991). By relaxing the assumptions of classical economics, rents (or excess profits) can be earned but only if barriers are in place to forestall movement towards the center of gravity. Several types of potential blockages and their attendant higher than 'normal' returns have been identified in the past (Monopoly, Ricardian, Pareto-Marshal, and Pareto rents; Peteraf, 1993).

Ricardian, Pareto-Marshall, and Pareto rents are earned in existing markets and are due either to superior resources (Ricardian), to better use of the resources in the firm than generally known in the marketplace (Pareto-Marshall), or to efficiencies (Pareto) in the use of the resources (Peteraf, 1993). Attempts to understand these rents and how they are generated and their strategic use have led researchers to develop transaction cost economics and agency theory, among others. These are perfectly appropriate theoretical orientations given the basis in an equilibrium understanding of the market and have provided useful viewpoints and increased our understanding of organizations and why certain decisions may be made in these conditions. However as presented earlier, this equilibrium view appears to be less useful in attempting to understand today's market characteristics and critical issues. 


\section{Disequilibrium Forces}

In Austrian economics, the market is in a state of disequilibrium, which provides opportunities to earn a variety of returns. While some argue that such returns are not rents because there is no long term equilibrium market upon which to calculate the average return (Hunt, 1995), the stock market in many instances does provide information which if not longitudinal certainly enables the determination of an industry average return for any point in time. To ease communication, "rents" will be used to indicate returns greater than the industry average at any point in time. These rents are similar to the rents possible in neoclassical economics but also include Schumpeterian rents and Entrepreneurial rents (E-rents). Schumpeterian rents occur as entrepreneurs take advantage of a revolutionary change in the market (McWilliam \& Smart, 1995). Entrepreneurial rent is associated with the initial market structuring activities of the entrepreneur. These disequilibrium rents are not earned because of a barrier keeping the market from movement towards equilibrium but because of the result of the changed market structure.

E-rents occur when a firm or entrepreneur enters or creates a previously unknown or unused competitive arena or market (Peteraf, 1993) and attempts to coordinate the market factors (Lachmann, 1977). The conditions (one or very few companies in the market) at this early stage mimic the conditions of a monopoly from equilibrium-based economic systems; however, monopolistic rents and entrepreneurial rents are distinctly different.

While both entrepreneurial and monopoly rents are due to a restriction in competition by firms, E-rents differ from monopoly rents in three ways: 1) in the lack of the previous identification of the competitive arena, 2) in the lack of deliberate restriction of output, and 3) in the lack of specific barriers to keep others from entering the market. E-rents are the entrepreneur's reward for taking on the risk of market coordination. This risk is associated with creating the initial market structure (which is assumed to be in place in equilibrium systems but not disequilibrium-based systems). Monopoly rents are obtained by deliberately attempting to hold the market process still. Monopoly rents are not rents generated from dynamism but static rents created by barriers.

Schumpeterian rents are the result of market restructuring activity. They reflect the risk that the entrepreneur takes to re-pupose his or her assets in a new way. It too is a reflection of the risk of market coordination but as a re-structuring activity and not as an initial market structuring activity. Yet it too is different from a monopoly rent in that the market is deliberately changed not deliberately refrained from movement.

Again, how are rents earned in this disequilibrium-based system? Rents are not necessarily earned through the creation of 'barriers' but through the very dynamics of the disequilibrium system. For example, if better performance occurs because a firm has a relatively better fit with the competitive environment (due to the entrepreneurial activities), then the earning of rents occurs because the firm attains a better fit than is anticipated by the market (due to 
inadequate information diffusion). Because of the lack of information, the complete set of fit requirements is not entirely known (see Austrian economics discussion earlier), a variety of such better-fit surprises can occur; which, therefore, enables multiple firms to generate rent.

However, with the generation of rents additional aspects of a current set of fit requirements are revealed (Ricketts, 1992). As the information about the returns available for any given fit is dispersed throughout the market place, potential competitors have access to the information. As firms choose to enter the revealed market (thereby utilizing the dispersed information), the density of firms in the market increases (Kirzner, 1982). It is this increased density coupled with a more complete diffusion of information about the market that enables each rent earned to be competed away. When there is increased market activity with a more complete diffusion of information, market dynamics are shifted to one that more closely resembles an equilibrium-based market. Given the inherent limits in noticing, gathering, interpreting, judging and utilizing information (March \& Simon, 1993) and the entrepreneurial alertness described earlier (Kirzner, 1982), the choice to enter or exit particular product markets is a result of the information use of entrepreneurs. Thus the driving force behind the rent cycle is the diffusion and use of information (Hayek, 1948b; Young, 1995).

It is interesting to note that the fit at the market level is inversely related to the fit at the firm level. The achievement of rents reveals that a relatively good fit for an individual firm has occurred. Yet, when the level of analysis is changed to the market, the earning of rents indicates that the degree of fit across all organizations is still relatively poor. The erosion of rents indicates that there is convergence on a particular fit and indicates a better overall degree of fit in the market. This provides further support for fit being relative not absolute. The organization that earns rents has the relatively better degree of fit.

Because rents (both equilibrium and disequilibrium uses) are higher than normal (survival) returns, firms attempt to earn them. Once earned and revealed to the competitive arena, the potential exists for what once conferred an advantage to become simply a needed element for competition (see above discussion of diffusion of information and also Barney, 1991). If others utilize the revealed information, the initial firm's relative fit as revealed by market performance may worsen. The lower-than-previous-times returns spark a reevaluation and potential modification of fit by that initial firm. The firm can either choose to hone the firm's fit in the current market or to attempt an entrepreneurial fitting in a new market (Black \& Farias, 2000).

The first possibility is to hone a firm's fit in the current market, in other words, to converge on a potential equilibrium point and to pursue Pareto, ParetoMarshall and Ricardian rents (Fabian and Black, 2001). The firm initiates a series of innovation rounds. If this innovation 'fits' it is indicated by the earning of rents. As other firms notice and respond to the innovation (DiMaggio \& Powell, 1983), the rate of return will decline to the degree that the competing firms have also created fit. When this happens, the firm can introduce Innova- 
tion 2 and the fitting dynamic repeats. With each innovation, the firm hones its fit by converging on the unknown ideal fit (which changes with each innovation) and subsequently reveals more about that elusive fit. The entrepreneurial firm may continue to hone or refine this fit as long as it is warranted. Several authors have argued that specific types of firm resources will be needed to engage in such convergence activities (Black, 1998; Fabian and Black, 2001). When the return rate drops below an acceptable level the firm may either change its definition of evidence of an acceptable fit (accept a different return rate), or look for another marketplace to create or enter (with the potential of earning the higher E-rents again).

Using this second way of higher return generation (moving to compete in a previously empty marketplace - Schumpeterian rent seeking — or to generate a brand new market - entrepreneurial rent seeking), the firm creates a fit for itself and reveals the new market structure. There are again specialized resources that enable these enterprising disequilibrium based actions (Fabian \& Black, 2001; Black and Farias, 2000; Black, 1998). Potential competitors who become aware of this new market now find themselves in misfit with this expanded environment. As competitors enter the new market, the honing of fit begins anew.

When a firm takes an early second mover orientation, both disequilibrium rents (entrepreneurial and Schumpeterian) and equilibrium based rents (efficiency/effectiveness rents) may be simultaneously earned. This occurs when the firm both successfully competes (whether via a different micro-niche in that market or via an equivalent fit) and also earns Ricardian, Pareto-Marshall or Pareto rents. Leapfrogging over the initial entrepreneurial firm can result in even larger total returns than those that the initial entrepreneurial firm earned when such activity reveals a much better fit with customers' needs and wants and is done much more efficiently (Teece, 1987; Gal-Or, 1985). While the mechanisms of such returns can come from either an understanding of equilibrium based systems (Mitchell, 1991; Rumelt et al., 1991; Teece, 1987) or from an understanding of disequilibrium based systems (Young, 1995), the point is that it is possible and reveals more information about that market.

The seeking of specific types of rent can reflect different drivers of fitting (Table 1). While Ricardian rents related to the inherent value of the resource being used and Pareto-Marshall rents related to the use of resources in ways not previously anticipated by the markets can be used in either a convergent or divergent fashion (rent seeking of either efficiency/effectiveness or entrepreneurial), the efficiency/effectiveness rents arising from Pareto rents reflect a convergent fitting process. Both entrepreneurial and Schumpeterian rent seeking reflects an orientation with a divergent fitting perspective since the new fit is differentiated from the previously identified fit. Recall that all rent seeking activities result in competitors reevaluating their own degree of fit. The interaction of the rent seeking (entrepreneurial and efficiency/effectiveness), the competitive cycle (information dispersal and ultimately rent erosion) and the fitting processes (convergent and divergent) constitute the fitting dynamic. Please note 
that within the same general markets but across time both equilibrium and disequilibrium forces may be in action. Such activities reveal that markets are complex systems (Anderson, 1999). As such, periods corresponding to defined patterns (equilibrium based assumptions more prominent) will alternate with periods of apparent chaos (disequilibrium based assumptions more prominent) (Black \& Farias, 2000). A description of the dynamics is presented next.

Table 1

Equilibrium-Disequilibrium Dynamics and Rent Generation

\begin{tabular}{ll}
\hline Dynamic Driver & Types of Rent \\
\hline Convergence & Ricardian, Pareto-Marshall, Pareto, Monopoly \\
Divergence & Ricardian, Pareto-Marshall, Entrepreneurial, Schumpeterian \\
\hline
\end{tabular}

\section{The Fitting Dynamic and the Marketplace}

The enacting of any organizations fitting choice in a marketplace causes the available information understood about that market as a whole to change. When noticed, this information stimulates competing organizations to reassess their degree of fit. The reassessment usually results in changes by the reassessing organizations; which, in turn, sparks reassessment by others. This type of a marketplace exhibits many features of a Boolean network system (Stacey, 1995). In such a system, any one element is connected to and both sends and receives signals to the others in the system. The current state of any element 'changes from moment to moment according to the information or energy it receives and the rules it follows for converting these to action or outputs' (Stacey, 1995; 487). This implies that the organizations in a competitive arena help create the changing or turbulent environment (albeit not all change in the environment is due to changes by the organizations inhabiting it).

\section{Implications from the Fitting Dynamic for Organization Studies}

Many organizational environments now are considered turbulent (Huber \& Glick, 1993), so not only does an organization need to engage in fitting, it needs to also coordinate its rate of change with that of the environment. Two illustrations of organizational fitting decision points beyond that of rent attenuation follow. First, a discontinuous change within a product-market environment (e.g. the advent of personal computers) will require a reassessment and a fitting dynamic choice of others within the market (Brothers Typewrites, etc.). Such discontinuous changes act as additional sources that need to be responded to and can potentially increase environmental turbulence.

Second, if an organization changes its current product-market environment leaving Market $A$ for Market $B$, it will simultaneously create better fit for the remaining current occupants of the Market $A$ environment, remove a source of information about Market $A$, and decrease the turbulence in Market $A$. The better 
fit occurs when the returns are spread over a smaller number of firms. The removal of the firm's actions reduce available information about that market, decreases the total number of potential respondents and responses, decreasing the stimuli that must be responded to by those who remain, finally resulting in a less turbulent environment. An example from the small business arena would be a used mobile home sales firm that chose to leave that industry and to move to the used car industry. By leaving the used mobile home sales industry, the firm allows the market share that it previously had to be split by the remaining firms in that industry in that area. There are thus fewer firms in the mobile home sales industry to pay attention to and to whom responses need to be made. Thus turbulence in that industry is reduced. By entering the used car industry, the firm increases the potential sales in that industry; this reveals that many of the same resources from the used mobile home sales may be used in the used car industry and increases the number of firms available to service that used car market. Turbulence is increased in the used car sales market.

Furthermore, the above two examples suggest that better fit may not be in the direction where the currently best performing organization is located now but in anticipating where it will be in the future. However, because the currently best performing organization reveals information about an environment, it reduces equivocality and will draw those who either cannot or choose not to reduce the equivocality and ambiguity inherent in the marketplace on their own. If successful, these secondary firms will also provide information about the market and help in the further spread of information about the market. It may not earn Erents but may earn any of the other rents. This action again reinforces the idea that firms use and are satisfied with different definitions of fit. Once moves are made, the remaining firms in the competitive arena reevaluate their fits and make their own moves.

Thus the fitting dynamic impacts the entire competitive environment. Because of the differing firm resources used in rent seeking based on honing to an existing market and those based on creating a new market structure, the choice of rents reveals the choice of resources to be used by a firm. Dynamic rents when considered in conjunction with a fitting process choice reveals resource-use implications (Black \& Farias, 2000; Fabian \& Black, 2001). When the type of rent seeking is explicitly known and the current use of a resource set is understood, a firm is in a better position to purposefully address the future. This information is valuable for decisions regarding both short and long-term issues and activities.

Just as an understanding of firm activity rooted in the equilibrium economic systems sparked streams of research to determine how effective that understanding was for both descriptive and predictive uses, a disequilibrium-based theoretical understanding should spark and/or reinvigorate streams even to the extent of possibly examining a new set of identified critical issues. For example, when focusing on a fitting dynamic instead of an end-state fit, critical areas include: information diffusion dynamics; continuing impact of technology espe- 
cially on communications; effective use of innovation and entrepreneurial activities; organizational learning; co-evolution of markets; the tensions between the potential results of strategies and specifics of implementations; the complex system nature of our environment and the implications for all involved. Indeed scholarly thinking and research has already begun in these areas (Anderson, 1999; Balabanis \& Reynolds, 2001; Bamford et al., 1999; Black, 1998; Braun, 2002; Engelland \& Alford, 2000; Fabian and Black, 2001; Garbi, 2002; Peteraf et al., 2002). These areas remain ripe for more research.

\section{Conclusion}

Because of the complex nature of the market, attainment of fit is elusive. Fit no longer is defined as an attainable 'end state' but rather as a relative state that is a process and is explicitly dynamic. The fitting dynamic helps explain action in complex markets such as those based on disequilibrium theories. Understanding the movement of firms in the market is possible by considering the two fitting dynamics of convergence and divergence and the resulting rent seeking activities. For example, consider the movements explained by examining the set of actions and reactions via the fitting dynamics involved of an entrepreneurial firm's fitting choices. If it chooses to converge on a current competitive arena fit, it may generate rents via the creation of the better fit while simultaneously causing the reevaluation by competitors of their own fits. The entrepreneurial firm may also choose to leave a current market for a new market. Whether or not it creates a better fit for itself, by just revealing the market, it creates the misfit of others for that newly revealed market.

By explicitly understanding that both convergence and divergence drivers are in play in the markets, opportunities to utilize resources thought only useful for convergence activities in divergence activities are more apparent. Many of these resources are ones that we already have looked at in narrower frameworks. Such resources needed for convergence activities include those associated with entrepreneurial awareness, thus early pattern recognition, information seeking, information gathering, information sifting/refinement to current uses, information dissemination, entrepreneurial opportunity spotting, entrepreneurship in its many forms, life-long learning skills, skills in shaping organizations to support such learning, and so on are typical organizational resources. Such resources can be found in individuals associated with the organization and/or in organizational structures. Examples of resources needed for divergence activities include full system understanding, power relationship understanding, creativity, innovation, entrepreneurship in its many forms, ability to vision, initiate, and successfully implement change and so on. The investment in and deployment of specific resources remains a task for the organization's leadership whether embodied in an individual or in each organizational member.

This view of fit as the explicit fitting dynamic helps us to begin to explain organizational activity in a richer way than fit has previously been presented. It 
confirms and highlights the importance of several strategic issues and provides a way to more closely analyze and determine a firm's strategic orientation. The fitting dynamic perspective builds on the previous definitions of fit while demonstrating the usefulness of studying the dynamics of the attainment of fit. An important aspect of this dynamic is the explanation of how firms who seek rents provide the driving force of the economy. Further areas of importance for new or renewed research include: 1) entrepreneurship and innovation; 2) information processing dynamics including both technological incorporation and intra-personal perceptual issues; 3 ) management of strategies in conditions of environmental dynamism and complexity; and 4) organizational learning and change in response to environmental change and as proactive influences in environmental change.

\section{References}

Addleson, M. (1994). Competition. In Peter J. Boettke (Ed.) The Elgar companion to Austrian economics. Hants, England: Edward Elgar Publishing Limited.

Anderson, P. (1999). Complexity theory and organization science. Organization Science, 10 (3), 216-232.

Argyres, N. \& McGahan, A. M. (2002) An interview with Michael Porter. Academy of Management Executive, 16 (2), 43-52.

Balabanis, G. \& Reynolds, N. L. (2001). Consumer attitudes towards multi-channel retailers' web sites: The role of involvement, brand attitude, internet knowledge and visit duration. Journal of Business Strategies, 18 (2), 105-132.

Bamford, C. E, Rogers, P. R, \& Miller, A. (1999). Transformation of strategic types: An examination of the internal antecedents to organizational change. Journal of Business Strategies, 16 (2), 135-150.

Barney, J. B. (1991). Firm resources and sustained competitive advantage. Journal of Management, 17, 99-120.

Black, J. A. (1998). Entrepreneur or entrepreneurs? Justification for a range of definitions. Journal of Business \& Entrepreneurship. 10 (1), 45-65.

Black, J. A. \& Farias, G. (2000). Dynamic strategies: Emergent journeys of entrepreneurs. Emergence, 2 (1), 101-113.

Braun, P. (2002). Digital knowledge networks: Linking communities of practice with innovation. Journal of Business Strategies, 19 (1), 43-54.

DiMaggio, P. J. \& Powell, W. W. (1983). The Iron cage revisited: Institutional isomorphism and collective rationality in organizational fields. American Sociological Review, 48, 147-160. 
Doty, D. H., Glick, W. H., \& Huber, G. P. (1993). Fit, equifinality, and organizational effectiveness: A test of two configurational theories. Academy of Management Journal, 36, 1196-1250.

Engeliand, B. T. \& Alford, B. L. (2000). Consumer learning and the creation of primacy advantages for followers. Journal of Business Strategies, 17 (2), 145-162.

Fabian, F. H. \& Black, J. A. (2001). Dominant strategic logic: Fractals of entrepreneurial conation and cognition. Proceedings of the 2001 Southwest Federation of Administrative Disciplines. Southwest Academy of Management Division, New Orleans, LA.

Gaglio, C. M. \& Katz, J. A. (2001) The psychological basis of opportunity identification: Entrepreneurial alertness. Small Business Economics, 16 (2), 95-111.

Gal-Or, E. (1985). First mover and second mover advantages. International Economic Review, 26 (3), 649-654.

Garrison, R. W. (1978). Austrian macroeconomics: A diagrammatical exposition. In Louis M. Spadaro (Ed.) New directions in Austrian economics. Kansas City, KS: Sheed Andrews \& McMeel Inc.

Garbi, E. (2002). Alternative measures of performance for E-companies: A comparison of approaches. Journal of Business Strategies, 19 (1), 1-17.

Giddens, A. (1979), Central problems in social theory. London: Macmillan.

Griner, W. (1977). In pursuit of the subjective paradigm. In W. Grinder (Ed.) Capital expectations and the market process. Kansas City, KS: Sheed Andrews \& McMeel Inc.

Huber. G. P. \& Glick, W. (1993). Sources and forms of organizational change. In G. P. Huber \& W. Glick (Eds.), Organizational change and redesign: Ideas and insights for improving performance, pp. 3-15. New York: Oxford University Press.

Hayek, F. A. (1948a). The competitive solution. In F. A. Hayek (Ed.) Individualism and economic order (pp 181-208). Chicago: University Press. (Reprinted from Economica, 1940, 7, 125-149.)

Hayek, F. A. (1948b). The use of knowledge in society. In F. A. Hayek (Ed.) Individualism and economic order (pp 181-208). Chicago: University Press. (Reprinted from American Economic Review, 1945, 35, 519-530).

Hunt, S. E. (1995). The resource-advantage theory of competition: Toward explaining productivity and economic growth. Journal of Management Inquiry, 4 (4), 3173332 . 
Hunt, S. D. (1998). Toward synthesizing resource-based, evolutionary, and neoclassical thought: The contribution of resource-advantage theory. In J. J. Foss and P. J. Robertson (Eds.) Resources, technology and strategy. Copenhagen: Copenhagen Business School.

Hunt, S. D. (2000). A general theory of competition: resources, competences, productivity, economic growth. Thousand Oaks, CA: Sage Publications.

Jacobson, R. (1992). The "Austrian" school of strategy. Academy of Management Review, 17 (4), 782-807.

Kirzner, I. M. (1978). Economics and error. In Louis M. Spadaro (Ed.) New directions in Austrian economics, Kansas City, KS: Sheed Andrews and McMeel Inc.

Kirzner, I. M. (1979). Comment: X-inefficiency, error and the scope for entrepreneurship. In Mario J. Rizzo (Ed.) Time, uncertainty and equilibrium. Lexington, MA: Lexington Books.

Kirzner, I. M. (1982). Uncertainty, discovery, and human action: A study of the entrepreneurial profile in the Misesian system. In I. M. Kirzner (Ed.) Method, process and Austrian economics. Lexington, MA: Lexington Books.

Kirzner I. M., (2000). (Ed.) The driving force of the market: Essays in Austrian economics. New York: Routledge.

Klein, P. G. (1992). Introduction. In Peter Klein (Ed.) The collected works of F. A. Hayek. Chicago: University of Chicago Press.

Lachmann, L. M. (1977). Austrian economics in the present crisis of economic thought. In Walter Grinder (Ed.) Capital, expectations and the market process. Kansas City, KS: Sheed, Andrews and McMeel Inc.

March, J. G. \& Simon, H. (1993) Organizations. 2nd ed. New York: Blackwell Publishers.

McWilliams, A. \& Smart, D., (1995). The resource-based view of the firm: Does it go far enough in shedding the assumptions of the S-C-P paradigm? Journal of Management Inquiry, 4 (4), 309-316.

Mintzberg, H. \& Waters, J. A. (1985). Of strategies, deliberate and emergent. Strategic Management Journal, 6 (3), 257-273.

Mitchell, W. (1991). Dual clocks: Entry order influences on incumbent and newcomer market share and survival when specialized assets retain their value. Strategic Management Journal, 12 (2), 85-101.

O'Driscoll, G. P. (1977). Spontaneous order and the coordination of economic activities. Journal of Libertarian Studies, 1, Spring, 137-151. 
Peteraf, M. A. (1993). The cornerstones of competitive advantage: A resource-based view. Strategic Management Journal 14, 179-191.

Peteraf, M. A. \& Ferrier, W. J. (2002). Conversations on the dynamics, context, and consequences of strategy: Introduction to a special issue. Managerial and Decision Economics, 23 (4/5), 149-156.

Ricketts, M. (1992). Kirzner's theory of entrepreneurship: A critique. In B. J. Caldwell \& S. Boehm (Eds.) Austrian economics: Tensions and new directions. Boston: Kluwer, 67-94.

Rumelt, R. P., Schendel, D., \& Teece, D. J. (1991). Strategic management and economics. Strategic Management Journal, 12, 5-30.

Scarth, W. M. (1988). Macroeconomics: An introduction to advanced methods. New York: Harcourt Brace Jovanovich.

Schumpeter, J. (1934). The theory of economic development. Cambridge, MA: Harvard University Press.

Stacey, R. D. (1995). The science of complexity: An alternative perspective for strategic change. Strategic Management Journal, 16 (6), 477-495.

Summer, C., Bettis, R, Duhaime, I., Grant, J., Hambrick, D., Snow, C., \& Zeithaml, C. (1990). Doctoral education in the field of business policy and strategy, 12, 167-183.

Teece, D. J. (1987). (Ed.) The competitive challenge: Strategies for industrial innovation and renewal. Cambridge, MA: Ballinger Pub. Co.

Van de Ven, A. \& Drazin, R. (1985). The concept of fit in contingency theory. In L. L. Cummings \& B. Staw (Eds.) Research in Organization Behavior, 7, 333-365. New York: JAI Press.

Venkatraman, S. (1997) The distinctive domain of entrepreneurship: An editor's perspective. In J. Katz and R. Brockhaus (Eds.), Advances in entrepreneurship, firm emergence and growth. New York: JAI Press.

von Mises, L. (1949). Human action: A treatise on economics. New Haven: Yale University Press.

von Mises, L. (1957). Theory and history: An interpretation of social and economic evolution. New Haven: Yale University Press.

Young, G. (1995). Comment: The resource-based view of the firm and "Austrian" economics: Integration to go beyond the S-C-P paradigm of industrial organization economics. Journal of Management Inquiry, 4 (4), 333 340 . 
Janice A. Black is Associate Professor in the Department of Management at New Mexico State University and international researcher/presenter. Her publication outlets include the Strategic Management Journal, Entrepreneurship, Theory \& Practice, and Advances in Applied Business Strategy. Her research is centered on the development of strategic implementation competencies such as entrepreneurship, creating a context for learning, leadership and strategic coherence. Her research and consulting work focuses on $R \& D$ and service industries and strategic alliances. 